\title{
Short-term effect of fine particulate matter and ozone on non-accidental mortality and respiratory mortality in Lishui district, China
}

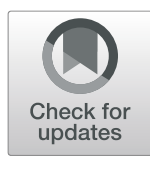

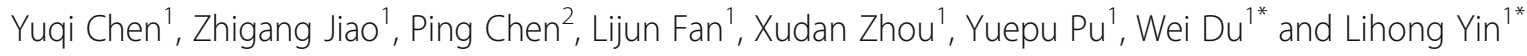

\begin{abstract}
Background: In recent years, air pollution has become an imminent problem in China. Few studies have investigated the impact of air pollution on the mortality of the middle-aged and elderly people. Therefore, this study aims to evaluate the impact of $\mathrm{PM}_{2.5}$ (fine particulate matter) and $\mathrm{O}_{3}$ (ozone) on non-accidental mortality and respiratory mortality of the middle-aged and elderly people in Lishui District of Nanjing and provide the evidence for potential prevention and control measures of air pollution.

Method: Using daily mortality and atmospheric monitoring data from 2015 to 2019, we applied a generalized additive model with time-series analysis to evaluate the association of $\mathrm{PM}_{2.5}$ and $\mathrm{O}_{3}$ exposure with daily nonaccidental mortality and respiratory mortality in Lishui District. Using the population attributable fractions to estimate the death burden caused by short-term exposure to $\mathrm{O}_{3}$ and $\mathrm{PM}_{2.5}$.

Result: For every $10 \mu \mathrm{g} / \mathrm{m}^{3}$ increase in $\mathrm{PM}_{2.5}$, non-accidental mortality increased $0.94 \%$ with $95 \%$ confidence interval (Cl) between 0.05 and 1.83\%, and $\mathrm{PM}_{2.5}$ had a more profound impact on females than males. For every $10 \mathrm{\mu g} / \mathrm{m}^{3}$ increase in $\mathrm{O}_{3}$, respiratory mortality increased $1.35 \%(95 \% \mathrm{Cl}: 0.05,2.66 \%)$ and $\mathrm{O}_{3}$ had a more profound impact on males than females. Compared with the single pollutant model, impact of the two-pollutant model on non-accidental mortality and respiratory mortality slightly decreased. In summer and winter as opposed to the other seasons, $\mathrm{O}_{3}$ had a more obvious impact on non-accidental mortality. The population attributable fractions of non-accidental mortality were $0.84 \%$ (95\% Cl:0.00, 1.63\%) for $\mathrm{PM}_{2.5}$ and respiratory mortality were $0.14 \%$ (95\% Cl: $0.01,0.26 \%)$ for $\mathrm{O}_{3}$. For every $10 \mu \mathrm{g} / \mathrm{m}^{3}$ decrease in $\mathrm{PM}_{2.5}, 122$ (95\% Cl: 6, 237) non-accidental deaths could be avoided. For every $10 \mu \mathrm{g} / \mathrm{m}^{3}$ decrease in $\mathrm{O}_{3}, 10(95 \% \mathrm{Cl}: 1,38)$ respiratory deaths could be avoided.

Conclusion: $\mathrm{PM}_{2.5}$ and $\mathrm{O}_{3}$ could significantly increase the risk of non-accidental and respiratory mortality in the middle-aged and elderly people in Lishui District of Nanjing. Exposed to air pollutants, men were more susceptible to $\mathrm{O}_{3}$ damage, and women were more susceptible to $\mathrm{PM}_{2.5}$ damage. Reduction of $\mathrm{PM}_{2.5}$ and $\mathrm{O}_{3}$ concentration in the air may have the potential to avoid considerable loss of lives.
\end{abstract}

Keywords: Air pollution, $\mathrm{O}_{3}, \mathrm{PM}_{2.5}$, Generalized additive model, Mortality

\footnotetext{
* Correspondence: duwei@seu.edu.cn; Ihyin@seu.edu.cn

'Key Laboratory of Environmental Medicine Engineering, Ministry of

Education, School of Public Health, Southeast University, Nanjing 210009,

China

Full list of author information is available at the end of the article
}

(C) The Author(s). 2021 Open Access This article is licensed under a Creative Commons Attribution 4.0 International License, which permits use, sharing, adaptation, distribution and reproduction in any medium or format, as long as you give appropriate credit to the original author(s) and the source, provide a link to the Creative Commons licence, and indicate if changes were made. The images or other third party material in this article are included in the article's Creative Commons licence, unless indicated otherwise in a credit line to the material. If material is not included in the article's Creative Commons licence and your intended use is not permitted by statutory regulation or exceeds the permitted use, you will need to obtain permission directly from the copyright holder. To view a copy of this licence, visit http://creativecommons.org/licenses/by/4.0/ The Creative Commons Public Domain Dedication waiver (http://creativecommons.org/publicdomain/zero/1.0/) applies to the data made available in this article, unless otherwise stated in a credit line to the data. 


\section{Background}

With economic development, air pollution has become an important risk factor to people's health. In 2019, air pollution ranked the fourth among the major risk factors of mortality in the world [1], causing 667 million deaths [2], comprising air pollutants such as particulate matter (PM) and ozone $\left(\mathrm{O}_{3}\right)$. Since the Chinese government implemented China's Action Plan of Prevention and Control of Air Pollution in 2013, concentration of $\mathrm{PM}_{2.5}$ (Particulate matter less than $2.5 \mu \mathrm{m}$ in aerodynamic diameter) has dropped significantly [3]. However, along with the rapid development of urban infrastructure and growth in motor vehicle number, ozone concentration has increased dramatically in recent years [4, 5]. Nonetheless, Wang et al. showed that in spite of the decrease of $\mathrm{PM}_{2.5}$ concentration in 74 cities of China from 2013 to 2018, $\mathrm{PM}_{2.5}$ was still more harmful to human health than $\mathrm{O}_{3}$ [6]. A coordinated prevention and control of $\mathrm{O}_{3}$ and $\mathrm{PM}_{2.5}$ pollution is possibly the focus of improvement in air quality in China [7].

A study found that short-term exposure to air pollution, particularly $\mathrm{PM}_{2.5}$, was associated with an increased risk of hospitalization for multiple disease entities [8]. Long-term or short-term exposure to air pollution were widely reported to associate with increased all-cause, respiratory, and/or circulatory mortality [9-13]. In addition, studies have shown that exposure to air pollutants was associated with risk of out-of-hospital cardiac arrest, diabetes, cancer, and increased risk of death and cognitive decline [14-18]. Exposure to $\mathrm{PM}_{2.5}$ and $\mathrm{O}_{3}$, is not only harmful to human health but also associated with a substantial disease burden [19] and economic loss [20]. Maji etal showed that the proportion of all-cause, cardiovascular and respiratory premature deaths attributed to short-term environmental $\mathrm{O}_{3}$ exposure in China in 2019 increased by 19.6, 19.8, and $21.2 \%$ in comparison with those in 2015, with the most significant increase in the respiratory premature deaths [21]. Moreover, the pathophysiological mechanism of air pollution on human health has shown that the primary initiation pathway of regulating the effect of air pollution on human health, originates from the airways, including pollutionmediated oxidative stress, local inflammation, and ion channels or receptor activation. It is clear that air pollution bears the brunt of harm to the respiratory system [22]. Studies have shown that improving air quality can significantly reduce the risk of death due to exposure to air pollutants [23].

With increasing age, the physiological functions of the respiratory system and multiple organs would decline especially among the middle-aged and elderly people, possibly leading to slow-down immune responses and increased allergic reactions [24, 25]. Therefore older adults are the major susceptible population to air pollution $[26,27]$. Considering $\mathrm{PM}_{2.5}$ and $\mathrm{O}_{3}$ are prominent local air pollutants, it is necessary to investigate the effects of short-term exposure to $\mathrm{PM}_{2.5}$ and $\mathrm{O}_{3}$ on nonaccidental mortality and respiratory mortality among the middle-aged and elderly. Of all studies on air pollution and mortality conducted in China, focus on rural and semi-rural areas is rare. Allowing for the rapid development and urbanization in rural China, our study stands for an important starting point demonstrating the example of disease burden in relation to possible environmental pollution. Findings may inform preventative policies and countermeasures in other settings similar to Lishui District, a rural district undergoing substantial infrastructure development and growing of consumption pollution-intensive resources.

\section{Materials and methods} Study area and population

Lishui District, one of the demonstration zone for Healthy China 2030, is located in the south of Nanjing, the capital city of Jiangsu Province. It has a northern subtropical monsoon climate with four distinct seasons, hot and humid in summer, cold and dry in winter. As of 2019, Lishui District has approximately 446,750 permanent residents, with an area of $1067 \mathrm{~km}^{2}$. We considered people aged 45 years and above as our study population.

\section{Study design \\ Data collection}

The daily death records and the daily average concentration of atmospheric pollutants in Lishui District from January 1, 2015 to December 31, 2019, were obtained from the Lishui Smart City Operating Command Center of Nanjing, the official data integration and management center of Lishui District government, which collects selected administrative data from different agencies after the calibration and verification, and therefore data accuracy is substantially high. Specifically, mortality data was originally collected from the Lishui Bureau of Public Security, and the environmental data was originally collected from the Lishui Bureau of Environmental and Ecological Protection. These two government agencies run regular data quality checks and there was no missing data for the current study setting.

The daily death records included the mortality data of the permanent population in Lishui. Specific information included age, gender, date of birth and the underlying cause of death. We categorized the causes of death based on the ICD-10 (International Statistical Classification of Diseases and Related Health Problems 10th Revision) diagnosis, i.e., non-accidental mortality (A00-R99), and respiratory diseases (J00-J99). The 
environmental data included daily meteorological and atmospheric pollutants measures.

\section{Statistical analysis}

We used the daily aggregated data from 2015 to 2019 to quantitatively assess the impact of $\mathrm{PM}_{2.5}$, and $\mathrm{O}_{3}$ exposure on non-accidental mortality and respiratory mortality. Daily mortality, air pollution, and meteorological data were described with average standard deviations and quartiles where appropriate. The relationship between air pollutants and meteorological conditions was evaluated using the spearman correlation. Mortality, air pollution, and meteorological data were linked by the date. Assuming that daily deaths in Lishui residents somewhat rare events and the correlation between explanatory variables and the number of deaths per day was mainly non-linear. Therefore, we constructed a generalized additive model (GAM) based on the Poisson distribution in which time-series analysis was used to establish the core model to estimate the association between mortality and air pollutant exposure. The model was specified as follows:

$$
\begin{aligned}
\log \left[E\left(Y_{t}\right)\right]= & \alpha+\beta X_{t}+n s(\text { Time, } d f)+n s\left(Z_{t}, d f\right) \\
& + \text { DOW }
\end{aligned}
$$

In this equation, $\mathrm{t}$ refers to the day of the observation; $Y_{t}$ is the number of daily mortalities observed on day $t$; $E\left(Y_{t}\right)$ is the expected daily mortality rate on day t. $\alpha$ is the intercept; $\beta$ represents the regression coefficient of the corresponding air pollutants; $X_{t}$ represents the pollutant concentration on day $\mathrm{t} ; \mathrm{Z}_{\mathrm{t}}$ represents the meteorological data on day $t$; DOW is a binary dummy variable; $\mathrm{s}$ is a non-linear variable with smoothing spline function. Previous studies have usually set the degrees of freedom (df) of time to 5 to 7 and meteorological factors to 3 to 6 [28-31]. The degree of freedom was selected according to the minimum value of the Akaike information criterion (AIC) of the Poisson model, and the smaller AIC value indicates the preferred model [32]. Considering the applicability and AIC value of the model, 6-df was used to adjust the time trend, seasonality, and temperature, whereas 3-df was used to adjust relative humidity in the model.

The lag effect of air pollutants on non-accidental mortality and respiratory mortality was modelled from the current day up to the 7th day (lag0-lag7). Previous studies have shown that cumulative effects may be underestimated by the single-day lag model [33]. Therefore, we further used the moving average of air pollutant concentrations from 2nd day to 8th day (lag01 to lag07) in the analysis. Considering that the decrease of $\mathrm{PM}_{2.5}$ might lead to the increase of photochemical flux and the acceleration of atmospheric oxidation, increasing of $\mathrm{O}_{3}$ concentration [34], we explored whether there is an interactive effect on the deaths arising from exposure to these two main pollutants in Lishui District by using the two-pollutant model to evaluate the confounding effect of pollutants. After establishing the statistical models that includes all control variables and checking the applicability, we separately included air pollutants into the model. Additional analyses were carried out stratified by gender (female and male), age group (45-64 years, 65-84 years, 85 years or older), or season (spring, summer, autumn, winter). Results were expressed as excess risk (ER) and 95\% confidence intervals (CI) of daily deaths associated with $10 \mu \mathrm{g} / \mathrm{m}^{3}$ increase in pollutants' concentration.

We further estimated the death burden attributable to short-term exposure to $\mathrm{O}_{3}$ and $\mathrm{PM}_{2.5}$. The counts of different death outcomes attributable to air pollutants were estimated using: $A C_{i j}=N_{i j} *\left(R R_{i j}-1\right) / R R_{i j}$, where $R R_{i j}$ is the relative risk for disease $\mathrm{j}$ at lagi based on the relative risk functions. $\mathrm{N}_{\mathrm{ij}}$ is the death number of disease $\mathrm{j}$ at lagi. $\mathrm{AC}_{\mathrm{ij}}$ is the attributable counts of disease $\mathrm{j}$ at lagi. We then calculated the total attributable counts of disease $\mathrm{j}\left(\mathrm{AC} \mathrm{C}_{\mathrm{j}}\right)$ by summing the $\mathrm{AC}_{\mathrm{ij}}$ of the study period. Finally, the population attributable fractions (PAF) were calculated by dividing the total $\mathrm{AC}_{\mathrm{j}}$ by the total number of deaths in the middle-aged and elderly people. All Statistical analysis was performed using $\mathrm{R}$ software, version 4.0.3. The statistical significance of all analyses was set as $P<0.05$.

\section{Result}

Table 1 shows the descriptive summary for daily mortality, air pollutants, and meteorological data in Lishui District of Nanjing during the period of 2015-2019. The total number of non-accidental mortality and respiratory mortality among the middle-aged and elderly ( $\geq 45$ years) in Lishui District was 13,160 and 1478 respectively. A seasonal pattern of daily mortality was also observed, with higher mortality in winter (Fig. 1). The daily average temperature was $16.90^{\circ} \mathrm{C}$ (Range: $-6.70{ }^{\circ} \mathrm{C}, 34.70{ }^{\circ} \mathrm{C}$ ), the daily relative humidity readings were measured in integers with an average of $72.99 \%$ (Range: $28,100 \%$ ). The 24-h $\mathrm{PM}_{2.5}$ concentrations were measured in integers with an average of $43.57 \mu \mathrm{g} / \mathrm{m}^{3}$ (Range: $26 \mu \mathrm{g} / \mathrm{m}^{3}$, $\left.171 \mu \mathrm{g} / \mathrm{m}^{3}\right)$. The maximum daily 8 -h concentrations of $\mathrm{O}_{3}$ (MDA8 $\mathrm{O}_{3}$ ) were measured in integers with an average of $100.13 \mu \mathrm{g} / \mathrm{m}^{3}$ (Range: $2 \mu \mathrm{g} / \mathrm{m}^{3}, 285 \mu \mathrm{g} / \mathrm{m}^{3}$ ). $\mathrm{O}_{3}$ concentration was to a moderate degree positively correlated with average temperature $(r=0.52, P<0.05)$, was to a moderate degree positively correlated with the relative humidity $(r=-0.38, P<0.05)$, and was slightly negatively correlated with $\mathrm{PM}_{2.5}$ concentration. $\mathrm{PM}_{2.5}$ was moderately correlated with the temperature $(r=-0.45$, 
Table 1 Daily deaths, air pollutants, and meteorological factors in Lishui district, 2015-2019

\begin{tabular}{|c|c|c|c|c|c|}
\hline Variables & Mean & SD & Min & P50 & Max \\
\hline \multicolumn{6}{|l|}{ Daily mortality counts } \\
\hline Non-accidental mortality & 7.21 & 2.90 & 0 & 7 & 19 \\
\hline Respiratory mortality & 0.81 & 0.96 & 0 & 1 & 6 \\
\hline \multicolumn{6}{|l|}{ Gender (n) } \\
\hline Male & 4.10 & 2.07 & 0 & 4 & 13 \\
\hline Female & 3.11 & 1.86 & 0 & 3 & 11 \\
\hline \multicolumn{6}{|l|}{ Age group (n) } \\
\hline 45-64 years & 1.60 & 0.82 & 1 & 1 & 6 \\
\hline $65-84$ years & 3.77 & 1.73 & 1 & 4 & 12 \\
\hline 85 years or older & 2.08 & 1.09 & 1 & 2 & 7 \\
\hline \multicolumn{6}{|l|}{$\mathrm{PM}_{2.5}\left(\mu \mathrm{g} / \mathrm{m}^{3}\right)$} \\
\hline All year & 43.57 & 25.05 & 4 & 38 & 171 \\
\hline Spring & 45.26 & 18.63 & 9 & 43 & 125 \\
\hline Summer & 29.25 & 15.65 & 4 & 26 & 141 \\
\hline Autumn & 36.84 & 18.19 & 10 & 34 & 146 \\
\hline Winter & 63.26 & 30.98 & 14 & 56 & 171 \\
\hline \multicolumn{6}{|l|}{$\mathrm{O}_{3}\left(\mu \mathrm{g} / \mathrm{m}^{3}\right)$} \\
\hline All year & 100.13 & 50.58 & 2 & 93.60 & 285.00 \\
\hline Spring & 117.68 & 45.36 & 11 & 113.00 & 252.00 \\
\hline Summer & 120.90 & 52.66 & 10 & 118.00 & 285.00 \\
\hline Autumn & 101.25 & 46.11 & 2 & 99.00 & 238.00 \\
\hline Winter & 59.90 & 30.39 & 2 & 59.00 & 176.00 \\
\hline \multicolumn{6}{|l|}{ Average temperature $\left({ }^{\circ} \mathrm{C}\right)$} \\
\hline All year & 16.91 & 9.07 & -6.70 & 17.80 & 34.70 \\
\hline Spring & 16.64 & 5.54 & 2.90 & 17.20 & 31.70 \\
\hline Summer & 27.36 & 3.28 & 18.70 & 27.20 & 34.70 \\
\hline Autumn & 18.07 & 5.65 & 0.10 & 17.90 & 29.30 \\
\hline Winter & 5.36 & 3.50 & -6.70 & 5.30 & 14.90 \\
\hline \multicolumn{6}{|l|}{ Relative humidity (\%) } \\
\hline All year & 72.99 & 13.99 & 28 & 73 & 100 \\
\hline Spring & 68.46 & 15.09 & 28 & 68 & 100 \\
\hline Summer & 76.95 & 10.70 & 49 & 77 & 100 \\
\hline Autumn & 75.20 & 12.77 & 42 & 75 & 100 \\
\hline Winter & 71.33 & 15.33 & 32 & 71 & 100 \\
\hline
\end{tabular}

Notes: Seasons were separated into Spring (Mar-May), Summer (Jun-August), Autumn (Sept-Nov) and Winter (Dec-Feb)

$P<0.05)$, and was slightly negatively correlated with the relative humidity (Fig. 2).

After adjusting for the time, day of the week, and weather conditions, we evaluated the single-day lag effect (lag0-lag7) and multi-day moving average lag effect (lag01-lag07) on non-accidental mortality and respiratory mortality (Fig. 3). For every increase in $\mathrm{PM}_{2.5}$ concentrations by $10 \mu \mathrm{g} / \mathrm{m}^{3}$, the greatest excessive risk of non-accidental mortality on the current day (lag0) increased by $0.94 \%$ (95\% CI: $0.05,1.83 \%$ ), and at lag7 the excessive risk of respiratory mortality increased by $0.57 \%$ (95\% CI: $-1.53,2.72 \%)$. For every increase in $\mathrm{O}_{3}$ concentration by $10 \mu \mathrm{g} / \mathrm{m}^{3}$, on the current day (lag0) the excessive risk of non-accidental mortality increased by $0.10 \%$ (95\% CI: $-0.46,0.67 \%$ ), and the greatest excessive risk of respiratory mortality at lag7 increased by $1.35 \%(95 \% \mathrm{CI}$ : $0.05,2.66 \%$ ). The increase of $\mathrm{PM}_{2.5}$ and $\mathrm{O}_{3}$ concentration had no statistical significance on the moving average lag effects of non-accidental mortality and respiratory mortality. To avoid multiple collinearities, only the two-pollutant model was used to detect the robustness of the model, and the multi-pollutant model was not considered. Compared with the single pollutant model, the results of the two-pollutant model had no significant change, and therefore the current model was somewhat robust (Table 2)

Tables 3 and 4 show the effect modification, after stratifying daily mortality by age, sex, and season. Figure 4 (a) shows that the single pollutant model, for every $10 \mu \mathrm{g} / \mathrm{m}^{3}$ increase in $\mathrm{PM}_{2.5}$, the greatest excessive risk of non-accidental mortality among middle-aged and elderly women on the current day (lag0) increased by $1.77 \%$ (95\% CI: $0.43,3.12 \%)$. There was no statistically significant difference in the effect of $\mathrm{PM}_{2.5}$ on male nonaccidental mortality $(P<0.05)$. Figure $4(\mathrm{~b})$ shows that in every $10 \mu \mathrm{g} / \mathrm{m}^{3}$ increase in $\mathrm{O}_{3}$ led to $1.38 \%$ (95\% CI: $0.30,2.47 \%)$ increase in respiratory mortality at lag7. And the effect of women was no statistical significance. Figure 5 shows that for every $10 \mu \mathrm{g} / \mathrm{m}^{3}$ increase in $\mathrm{O}_{3}$, non-accidental mortality in summer and winter increased by $0.75 \%$ (95\% CI: $0.01,1.50 \%)$ and $1.38 \%(0.30$, $2.47 \%)$ at lag2 and lag5 respectively. The effect of $\mathrm{O}_{3}$ on non-accidental mortality was not statistically significant in spring and autumn $(P>0.05)$. The increase of $\mathrm{PM}_{2.5}$ and $\mathrm{O}_{3}$ concentrations has different maximum lag effects in different age groups, but the effect is not statistically significant.

Table 5 shows the numbers and fractions of nonaccidental mortality and respiratory mortality attributable to air pollutants among the middle-aged and elderly in Lishui district. The Population Attributable Fractions (PAF) of non-accidental mortality were $0.84 \%$ (95\% CI: $0.00,1.63 \%)$ for $\mathrm{PM}_{2.5}$ and the PAF of respiratory mortality were $0.14 \%$ (95\% CI: $0.05,0.26 \%$ ) for $\mathrm{O}_{3}$. Every $10 \mu \mathrm{g} / \mathrm{m}^{3}$ decrease in $\mathrm{PM}_{2.5}$ could save 122 (95\% CI: 6, 237) people from non-accidental deaths, and every $10 \mu \mathrm{g} / \mathrm{m}^{3}$ decrease in $\mathrm{O}_{3}$ could save 10 (95\% CI: 1, 38) people from respiratory deaths.

\section{Discussion}

This study used a time-series model to investigate the relationship between exposure of air pollutants $\left(\mathrm{PM}_{2.5}\right.$ and $\mathrm{O}_{3}$ ) and non-accidental mortality and respiratory 


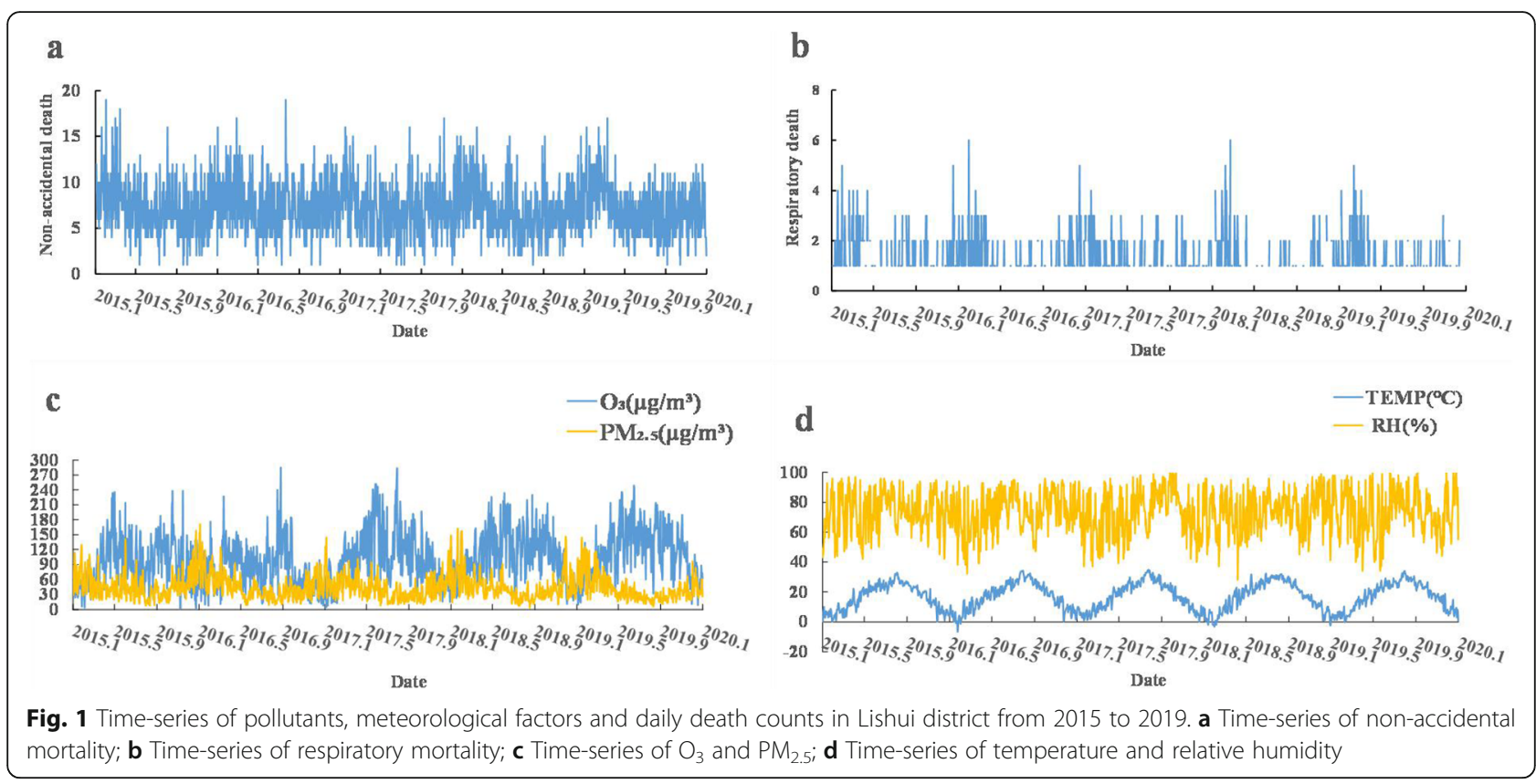

mortality in Lishui District of Nanjing, Jiangsu Province, China from 2015 to 2019. Results showed that shortterm exposure to $\mathrm{PM}_{2.5}$ and $\mathrm{O}_{3}$ was positively correlated with an increased risk of non-accidental and respiratory mortality. The daily average concentration of $\mathrm{PM}_{2.5}$ was $43.57 \mu \mathrm{g} / \mathrm{m}^{3}$, which was higher than the National Ambient Air Quality Standard (NAAQS) first-level standard, but lower than the second-level standard (the first-level standard is $35 \mu \mathrm{g} / \mathrm{m}^{3}$, the second-level standard is $75 \mu \mathrm{g} / \mathrm{m}^{3}$ ). The MDA8 $\mathrm{O}_{3}$ was $100.13 \mu \mathrm{g} / \mathrm{m}^{3}$, which was also higher

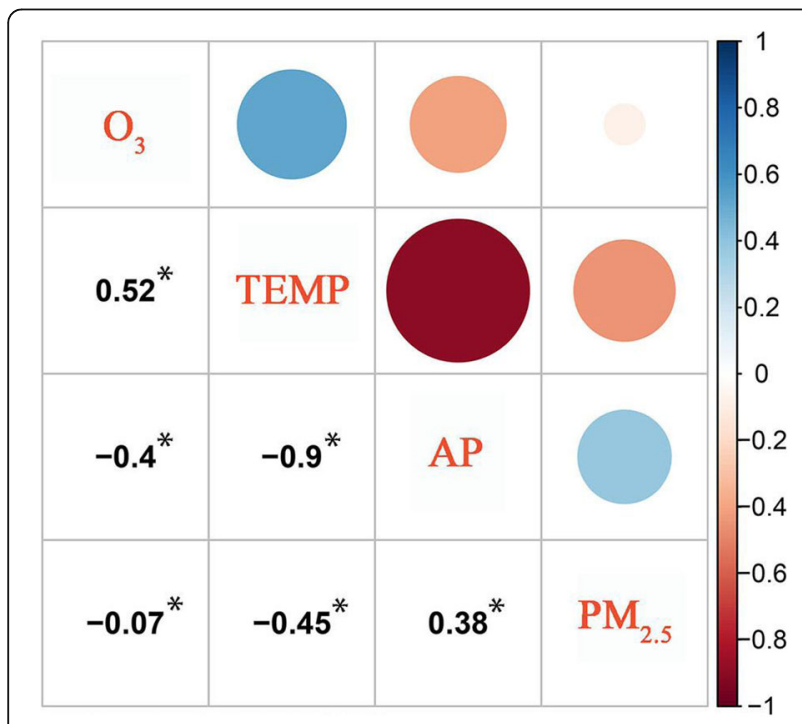

TEMP: temperature; RH: relative humidity $\left({ }^{*} P<0.05\right)$

Fig. 2 Spearman correlation coefficients between daily air pollutants and meteorological parameters than the NAAQS first-level standard, but lower than the second-level standard (the first-level standard is $100 \mu \mathrm{g} /$ $\mathrm{m}^{3}$ and the second-level standard is $160 \mu \mathrm{g} / \mathrm{m}^{3}$ ). The seasonal fluctuation of air pollution demonstrated that $\mathrm{PM}_{2.5}$ concentrations were higher in spring and winter than in summer and autumn and reached its peak in summer, whereas $\mathrm{O}_{3}$ concentrations were higher in summer and autumn than in spring and winter, and peaked in winter. A seasonal pattern in the number of daily deaths was also observed, with higher mortality in winter. This observed seasonal fluctuation may be related to the increase in pollutants. For example, industrial activities and combustion emissions in winter are more frequent to produce more $\mathrm{PM}_{2.5}$ [35], whereas high temperature and sufficient sunshine in summer are favorable conditions for photochemical reaction to produce $\mathrm{O}_{3}$ [36]. Using chemical industrial solvents and emitting the volatile organic compounds and nitrogen oxides from automobile exhaust may cause high levels of $\mathrm{O}_{3}$ as well [37].

We found that in the single pollutant model, $\mathrm{PM}_{2.5}$ demonstrated acute effects on non-accidental mortality. Every $10 \mu \mathrm{g} / \mathrm{m}^{3}$ increase in $\mathrm{PM}_{2.5}$ was associated with a 0.94\% (95\% CI: $0.05,1.83 \%)$ increase in non-accidental mortality at lag0. A study conducted in a highly polluted area in China found that $10 \mu \mathrm{g} / \mathrm{m}^{3}$ increase in $\mathrm{PM}_{2.5}$ was associated with $0.36 \%$ (95\% CI: $0.10,0.63 \%$ ) increase of non-accidental mortality [38]. Lin et al. found that every $10 \mu \mathrm{g} / \mathrm{m}^{3}$ increase in $\mathrm{PM}_{2.5}$ was associated with $1.50 \%$ (95\% CI: $0.50-2.50 \%$ ) of non-accidental mortality among the elderly aged over 65 years [39]. A study conducted in 75 cities in the United States showed that for every $10 \mu \mathrm{g} / \mathrm{m}^{3}$ increase in $\mathrm{PM}_{2.5}$, the non-accidental mortality 
a

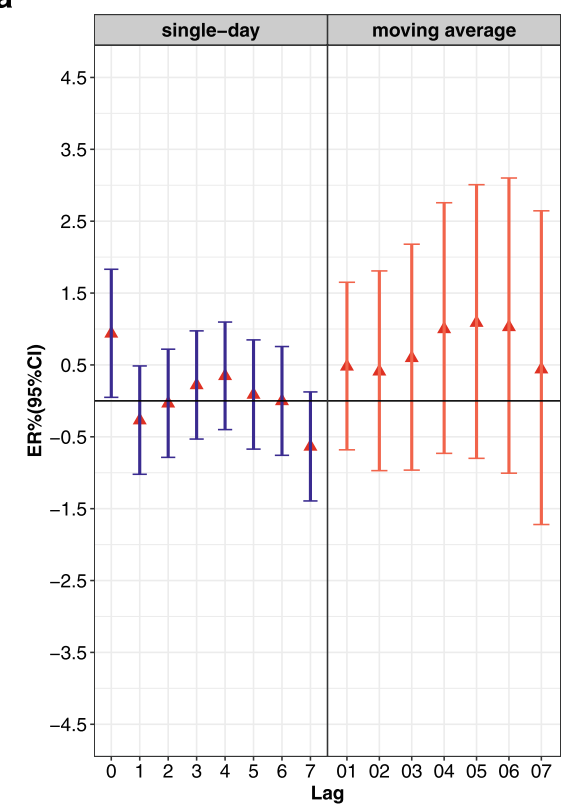

b

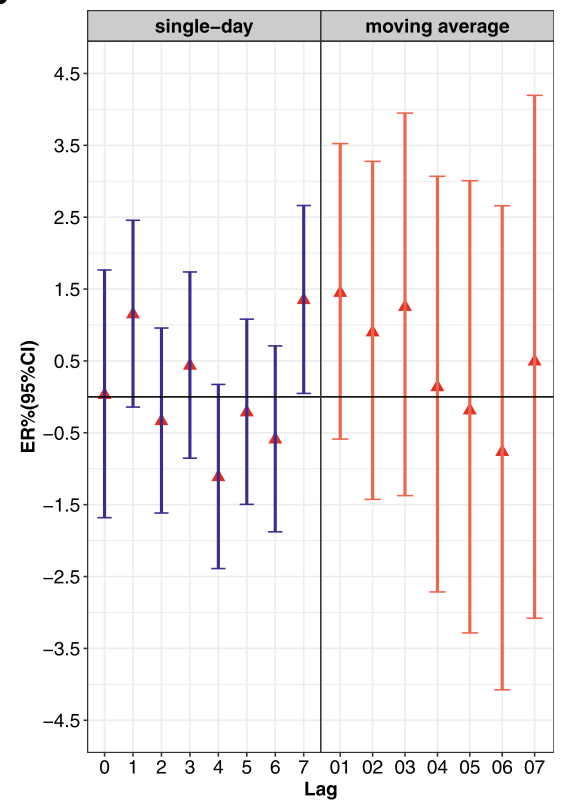

Fig. 3 The ER $(95 \% \mathrm{Cl})$ associated with $10 \mu \mathrm{g} / \mathrm{m}^{3}$ increase of mortality; a $\mathrm{PM}_{2.5}$ led to non-accidental mortality; $\mathbf{b} \mathrm{O}_{3}$ led to respiratory mortality

rate increased by $1.18 \%$ (95\% CI: $0.93,1.44 \%$ ) [40]. Another large-scale study involving multiple countries and regions found that for every $10 \mu \mathrm{g} / \mathrm{m}^{3}$ increase in $\mathrm{PM}_{2.5}$, the daily non-accidental mortality rate increased by 0.68\% (95\% CI: 0.59, 0.77\%) [41]. Although our results showed that the impact of $\mathrm{PM}_{2.5}$ on non-accidental mortality in Lishui District was slightly higher, it was generally consistent with the results of previous research reports in China. This difference may be mainly related to the difference with study settings, for example the age difference of the exposed population. Moreover, the sources and chemical composition of $\mathrm{PM}_{2.5}$ in different regions are different, which may also lead to different effects on mortality.

We also found that $\mathrm{O}_{3}$ had acute effects on respiratory mortality. Every $10 \mu \mathrm{g} / \mathrm{m}^{3}$ increase in $\mathrm{O}_{3}$ was associated with an increase in respiratory disease mortality by $1.35 \%$ (95\% CI: $0.05,2.66 \%)$ at lag7. A study in Jinan showed that Every $10 \mu \mathrm{g} / \mathrm{m}^{3}$ increase in $\mathrm{O}_{3}$ was associated with a $0.98 \%$ (95\% CI: $0.46,1.49 \%)$ increase in respiratory mortality at lag3 [42]. Another study in Hefei showed that every $10 \mu \mathrm{g} / \mathrm{m}^{3}$ increase in $\mathrm{O}_{3}$ led to a $2.22 \%$ (95\% CI: $0.56,3.90 \%$ ) increase in respiratory mortality [38]. A Sichuan study found that every $10 \mu \mathrm{g} / \mathrm{m}^{3}$ increase in $\mathrm{O}_{3}$ led to a $0.78 \%$ (95\% CI: $0.12,1.44 \%$ ) increase in respiratory mortality [43]. Our finding was consistent with the previous results [44-46]. With the rapid development of the economic level and the acceleration of the urbanization process, the production of industrial manufacturing was also increasing, which may lead to the increase of volatile organic compounds (VOCs) emissions [47]. This may be one of the reasons that $\mathrm{O}_{3}$ in Lishui District had a greater impact on the respiratory mortality in the middle-aged and elderly population. In this study, the impact of multi-day moving average lag was higher than that of single-day lag, but the effect was not statistically significant, which was also consistent with the previous results [48].

Subgroup analysis showed that air pollutants were significantly related to non-accidental and respiratory

Table 2 The excess risk ( $95 \%$ Cl) of daily mortality associated with $10 \mu \mathrm{g} / \mathrm{m}^{3}$ increase

\begin{tabular}{llr}
\hline Variables & Non-accidental mortality & Respiratory mortality \\
\hline $\mathbf{P M}_{\mathbf{2 . 5}}$ & & \\
$\quad$ Single pollutant model & $0.9363 \%(0.0492,1.8312 \%)^{*}$ & $0.6029 \%(-1.5060,2.7571 \%)$ \\
$\quad+\mathrm{O}_{3}$ & $0.9359 \%(0.0366,1.8434 \%)^{*}$ & $0.6026 \%(-1.5069,2.7572 \%)$ \\
$\mathbf{O}_{\mathbf{3}}$ & & \\
Single pollutant model & $0.1501 \%(-0.2682,0.5701 \%)$ & $1.3469 \%(0.0479,2.6627 \%)^{*}$ \\
$\quad+\mathrm{PM}_{2.5}$ & $0.1460 \%(-0.2722,0.5659 \%)$ & $1.3384 \%(0.0363,2.6574 \%)^{*}$ \\
\hline
\end{tabular}


Table 3 The non-accidental maximum ER (95\% Cl) in lag days, stratified by age, sex and season

\begin{tabular}{|c|c|c|c|c|}
\hline \multirow[t]{2}{*}{ Variables } & \multicolumn{4}{|c|}{ Non-accidental deaths } \\
\hline & Lag & $\mathrm{PM}_{2.5}$ & Lag & $\mathrm{O}_{3}$ \\
\hline All & Lag0 & $0.94 \%(0.05,1.83 \%)^{*}$ & Lag1 & $0.15 \%(-0.27,0.57 \%)$ \\
\hline \multicolumn{5}{|l|}{ Age(yeas) } \\
\hline $45-64$ & Lag0 & $0.99 \%(-1.34,3.37 \%)$ & $\operatorname{Lag} 1$ & $0.31 \%(-0.92,1.54 \%)$ \\
\hline $65-84$ & Lag5 & $1.04 \%(-2.30,4.51 \%)$ & Lag7 & $0.25 \%(-0.40,0.90 \%)$ \\
\hline $85+$ & Lag0 & $1.13 \%(-0.63,2.91 \%)$ & Lag0 & $0.52 \%(-0.63,1.68 \%)$ \\
\hline \multicolumn{5}{|l|}{ Sex } \\
\hline Male & Lag4 & $0.29 \%(-0.70,1.29 \%)$ & Lag1 & $0.16 \%(-0.40,0.71 \%)$ \\
\hline Female & Lag0 & $1.77 \%(0.43,3.12 \%)^{*}$ & Lag0 & $0.67 \%(-0.18,1.53 \%)$ \\
\hline \multicolumn{5}{|l|}{ Season } \\
\hline Spring & Lag0 & $1.12 \%(-1.43,3.72 \%)$ & Lag4 & $0.60 \%(-0.33,1.53 \%)$ \\
\hline Summer & Lag5 & $2.38 \%(-0.11,4.94 \%)$ & Lag5 & $0.75 \%(0.01,1.50 \%)^{*}$ \\
\hline Autumn & Lag3 & $1.09 \%(-1.02,3.24 \%)$ & Lag0 & $0.45 \%(-0.93,1.85 \%)$ \\
\hline Winter & Lag0 & $0.96 \%(-0.38,2.33 \%)$ & Lag2 & $1.38 \%(0.30,2.47 \%)^{*}$ \\
\hline
\end{tabular}

mortality in different genders and seasons. Women were more susceptible to $\mathrm{PM}_{2.5}$ in terms of non-accidental mortality. This was consistent with the Shin et al. study [49] and $\mathrm{Hu}$ et al. study [50]. Women may have stronger airway responsiveness in addition to hormones or other factors, and therefore women might have a stronger physiological response to air pollutants [51, 52]. However, there was also conflicting evidence that men were more susceptible to the impact of $\mathrm{PM}_{2.5}$ on nonaccidental mortality $[53,54]$. In contrast, we found that men were more susceptible to the effects of $\mathrm{O}_{3}$ on respiratory mortality than women. A research carried out in Shenzhen also found the similar result [55], which could be explained by the fact that pneumonia and bronchitis were more commonly observed in men who had a smoking history and different occupational exposures, which may exacerbate the impact of $\mathrm{O}_{3}$ on respiratory mortality [56].

The $\mathrm{O}_{3}$ concentration in summer had a statistically significant effect on non-accidental mortality. This is consistent with the finding of Zanobetti et al. [57], allowing for that in summer the ozone precursor substances in the air produce $\mathrm{O}_{3}$ faster as the temperature rises [58]. We also found that although the concentration of $\mathrm{O}_{3}$ in winter was at the lowest level throughout the year, the effect of $\mathrm{O}_{3}$ on non-accidental mortality was also substantial. A study in Nanjing found that the concentration of indoor $\mathrm{O}_{3}$ in winter may be greater than that of outdoor $\mathrm{O}_{3}$ [59], and therefore impact of $\mathrm{O}_{3}$ exposure on excess deaths might be underestimated in the current study. Research conducted in East Asia found that $\mathrm{O}_{3}$ levels in different seasons have varying degrees of impact on non-accidental mortality [60], which indicates potential geographical heterogeneity [61]. To identify susceptible groups, we also explored the potential modification effects of age, but in our study, we did not observe significant modification effects of age groups.

In the attributable fraction analysis, nearly $0.84 \%$ of non-accidental mortality can be attributable to $\mathrm{PM}_{2.5}$, and reduction in the concentration of $\mathrm{PM}_{2.5}$ could save 122 (95\% CI: 6, 237) lives of the middle-aged and elderly people. In addition, $0.14 \%$ respiratory mortality can be attributable to $\mathrm{O}_{3}$, and reduction in the concentration of $\mathrm{O}_{3}$ could save 20 (95\% CI: 1, 38) lives of middle-aged and elderly people. This finding highlights the gain in population health and reduction in disease burden in association with air pollution. Therefore, relevant

Table 4 The respiratory maximum ER (95\% Cl) in lag days, stratified by age, sex and season

\begin{tabular}{|c|c|c|c|c|}
\hline \multirow[t]{2}{*}{ Variables } & \multicolumn{4}{|c|}{ Respiratory deaths } \\
\hline & Lag & $\mathrm{PM}_{2.5}$ & Lag & $\mathrm{O}_{3}$ \\
\hline All & Lag2 & $0.60 \%(-1.51,2.76 \%)$ & Lag7 & $1.35 \%(0.05,2.66 \%)^{*}$ \\
\hline \multicolumn{5}{|l|}{ Age(year) } \\
\hline $45-64$ & Lag0 & $0.39 \%(-15.11,18.71 \%)$ & Lag4 & $0.39 \%(-11.35,13.67 \%)$ \\
\hline $65-84$ & Lag5 & $1.04 \%(-2.30,4.51 \%)$ & Lag5 & $0.69 \%(-1.36,2.79 \%)$ \\
\hline $85+$ & Lag0 & $0.59 \%(-3.27,4.60 \%)$ & Lag4 & $0.11 \%(-2.21,2.48 \%)$ \\
\hline \multicolumn{5}{|l|}{ Sex } \\
\hline Male & Lag4 & $1.03 \%(-1.65,3.78 \%)$ & Lag7 & $2.06 \%(0.41,3.74 \%)^{*}$ \\
\hline Female & Lag0 & $2.21 \%(-1.73,6.30 \%)$ & Lag0 & $1.12 \%(-1.55,3.87 \%)$ \\
\hline \multicolumn{5}{|l|}{ Season } \\
\hline Spring & Lag0 & $2.49 \%(-4.92,10.47 \%)$ & Lag5 & $1.50 \%(-1.41,4.50 \%)$ \\
\hline Summer & Lag6 & $7.76 \%(-0.11,16.25 \%)$ & Lag3 & $1.19 \%(-1.14,3.58 \%)$ \\
\hline Autumn & Lag6 & $3.26 \%(-3.81,10.85 \%)$ & Lag6 & $0.14 \%(-2.93,3.31 \%)$ \\
\hline Winter & Lag7 & $1.97 \%(-0.87,4.90 \%)$ & Lag4 & $2.16 \%(-0.87,5.29 \%)$ \\
\hline
\end{tabular}


a

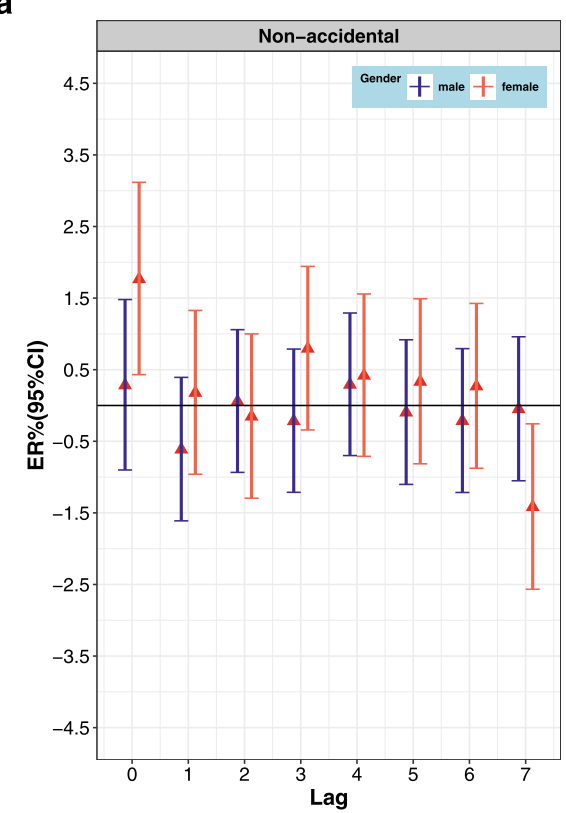

b

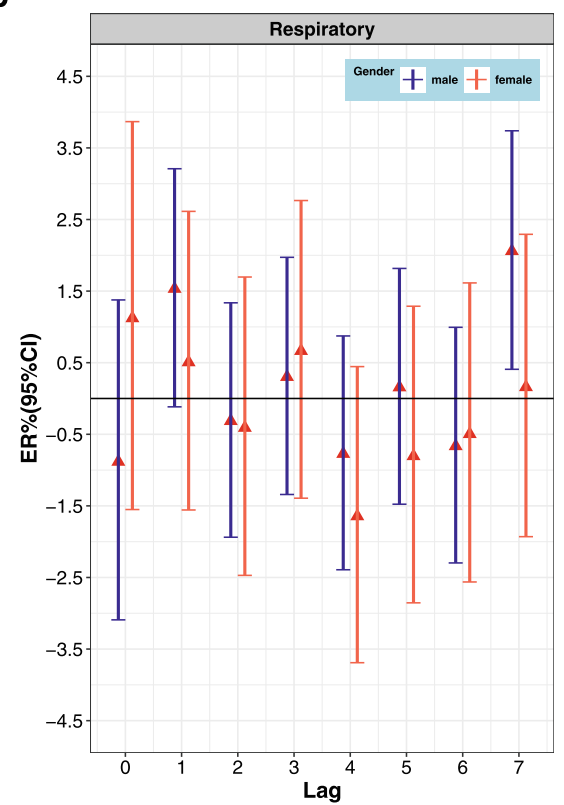

Fig. 4 The ER $(95 \% \mathrm{CI})$ in gender lag-response relationship associated with $10 \mu \mathrm{g} / \mathrm{m}^{3}$ increase of mortality; a PM 2.5 led to non-accidental mortality; b $\mathrm{O}_{3}$ led to respiratory mortality

authorities in Lishui District might take measures to improve the quality of atmospheric environment to enhance population health.

Considering the impact on respiratory mortality as perhaps the most direct effect caused by environmental pollutants during the contact with airways, our study selected the most prominent atmospheric pollutants
$\mathrm{PM}_{2.5}$ and $\mathrm{O}_{3}$ in Lishui District and analyzed their relationship with the mortality of the study population. Previous studies on respiratory mortality in relation to atmospheric pollutants demonstrated inconsistent findings. For example, ozone was found having little impact on the non-accidental deaths in Hefei, capital city of Anhui province in China [62]. Our findings add to the

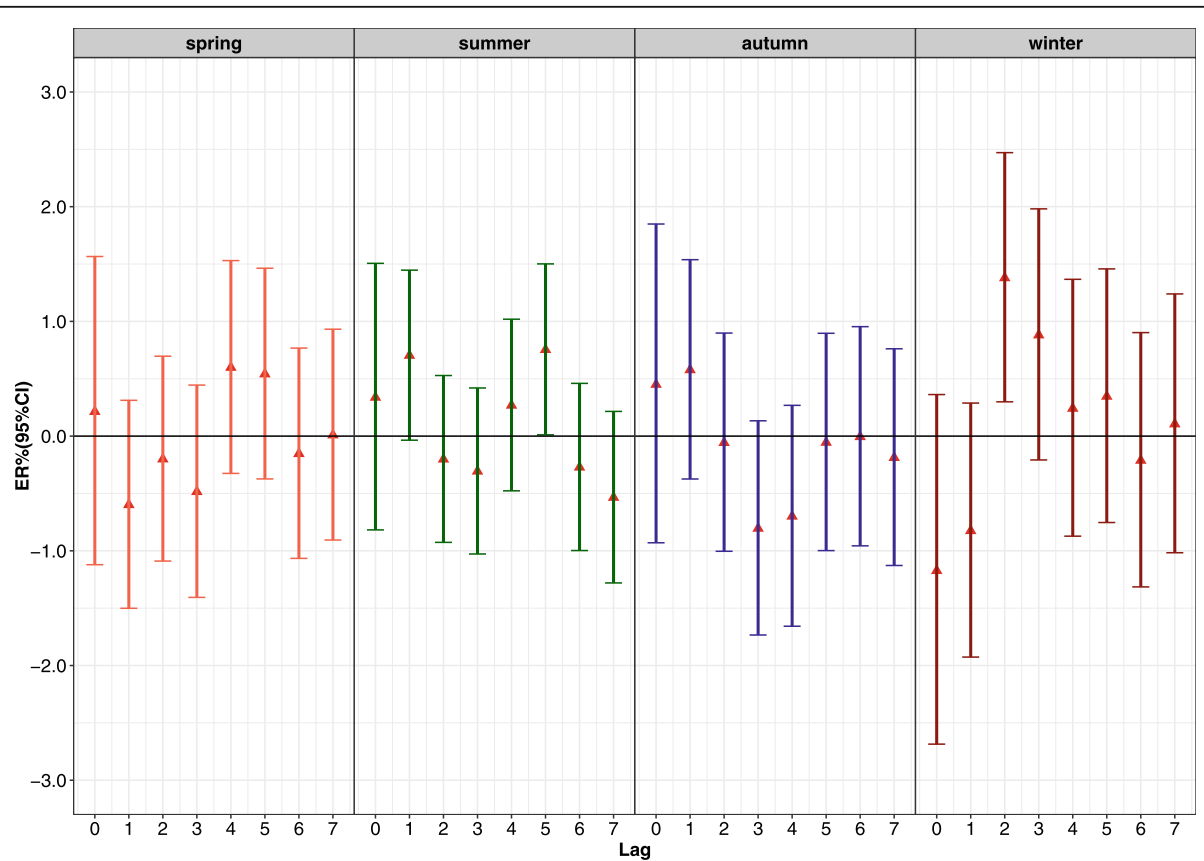

Fig. 5 The ER $(95 \% \mathrm{Cl})$ in season lag-response relationship associated with $10 \mu \mathrm{g} / \mathrm{m}^{3}$ increase of $\mathrm{O}_{3}$ led to non-accidental mortality 
Table 5 PAC $(95 \% \mathrm{Cl})$ and PAF $(95 \% \mathrm{Cl})$ in association with air pollutants in 2015-2019

\begin{tabular}{llll}
\hline & Pollutants & PAC (95\% Cl) & PAF (95\% Cl) \\
\hline Non-accidental mortality & $\mathrm{PM}_{2.5}$ & $122(6,237)$ & $0.84 \%(0.00,1.63 \%)$ \\
Respiratory mortality & $\mathrm{O}_{3}$ & $20(1,38)$ & $0.14 \%(0.05,0.26 \%)$ \\
\hline
\end{tabular}

Note: PAC: Population Attributable Counts; PAF: Population Attributable Fractions

literature by providing a new evidence of the relationship between respiratory mortality and atmospheric pollutants $\mathrm{PM}_{2.5}$ and $\mathrm{O}_{3}$.

This study has some limitations. First, we used the average concentration of air pollutants recorded at the monitoring sites as the population exposure level, without considering the indoor exposure. This would lead to exposure measurement errors and deviations in the accuracy and intensity of risk estimates. Secondly, the daily mean death number due to respiratory diseases might be too low to draw a safe conclusion. The results cannot be extrapolated to the entire Nanjing or other regions of China, and therefore results should be interpreted with caution. Moreover, this study did not collect information on smoking history, body mass index, drug history, and educational level. These potential confounding factors may also have a latent impact on the association between air pollution and mortality. In the two-pollutant model, the effect of each pollutant on non-accidental and respiratory mortality was reduced, which was inconsistent with previous studies $[38,62]$. Considering concentrations of $\mathrm{PM}_{2.5}$ and $\mathrm{O}_{3}$ varied in an opposite way by seasons, for example, higher $\mathrm{PM}_{2.5}$ concentrations in winter but higher $\mathrm{O}_{3}$ concentrations in summer, a possible offset function would explain the observed inconsistency. Nonetheless, future studies would be carried out to investigate the joint effects of these two pollutants.

\section{Conclusion}

This study shows that among the middle-aged and elderly residents in Lishui District of Nanjing, China, shortterm exposure to $\mathrm{PM}_{2.5}$ and $\mathrm{O}_{3}$ would increase the risk of non-accidental death and respiratory death. Our findings complement previous studies by revealing that air pollutants have a lag effect on the health of the population in rural areas undergoing rapid socioeconomic development. These findings call for new initiatives including implementation of more stringent air pollutant emission control policies to improve population health.

\footnotetext{
Abbreviations

$\mathrm{O}_{3}$ : Ozone; PM: Particulate matter; $\mathrm{PM}_{2.5}$ : Particulate matter less than $2.5 \mu \mathrm{m}$ in aerodynamic diameter; $\mathrm{Cl}$ : Confidence intervals; MDA8 $\mathrm{O}_{3}$ : Maximum daily maximum 8-h average concentration; TEMP: temperature; $\mathrm{RH}$ : relative humidity; NAAQS: National Ambient Air Quality Standard; ICD10: International Statistical Classification of Diseases and Related Health Problems 10th Revision; GAM: Generalized additive model; ER: Excess risk; df: degrees of freedom; AIC: Akaike information criterion; PAF: Population attributable fractions; PAC: Population Attributable Counts
}

\section{Acknowledgements}

The authors are grateful for the financial supports by the National Natural Science Foundation of China (Nos. 81872588, 82073516). We thank the People's Government of Lishui district of Nanjing, the Lishui Smart City Operating Command Center, the Lishui Bureau of Public Security, and the Lishui Bureau of Environmental and Ecological Protection for providing research data and strong support for the study.

\section{Authors' contributions}

YQC, LHY and WD conceived and designed the work. YQC, LJF, PC, XDZ, WD, YPP and LHY contributed to data acquisition and preparation, YQC and ZGJ were involved in the study design and the interpretation of the results. LHY provided important feedback on how the study can be improved. YQC and ZGJ drafted the manuscript and LHY revised the manuscript. All authors approved the final manuscript.

\section{Funding}

This work was supported by the Program of National Natural Science Foundation of China (Nos. 81872588, 82073516).

\section{Availability of data and materials}

The datasets generated and/or analyzed during the current study are not publicly available due to the sensitive nature of the raw data and restrictions apply to the availability of the raw data.

\section{Declarations}

\section{Ethics approval and consent to participate}

The Institutional Ethics Committee for Clinical Research of Zhongda Hospital Affiliated to Southeast University, approved the study protocol (No. 2020ZDSYLL266-P01). There were no human or animal experiments in this study. All methods were performed in accordance with the relevant guidelines and regulations. Data were analyzed at the aggregate level and no participants were contacted.

\section{Consent for publication \\ Not applicable.}

\section{Competing interests}

The authors declare that they have no actual or potential competing financial interests.

\section{Author details}

${ }^{1}$ Key Laboratory of Environmental Medicine Engineering, Ministry of Education, School of Public Health, Southeast University, Nanjing 210009,

China. ${ }^{2}$ Lishui Smart City Operating Command Center, Lishui 211200, China.

Received: 12 May 2021 Accepted: 29 August 2021

Published online: 13 September 2021

\section{References}

1. Health Effects Institute. State of global air 2020. Boston: Health Effects Institute; 2020. https://www.stateofglobalair.org/.

2. Murray CJL, Aravkin AY, Zheng P, Abbafati C, Abbas KM, Abbasi-Kangevari $M$, et al. Global burden of 87 risk factors in 204 countries and territories, 1990-2019: a systematic analysis for the global burden of disease study 2019. Lancet. 2020;396(10258):1223-49. https://doi.org/10.1016/S0140-6736(2 0)30752-2.

3. Zhang Q, Zheng Y, Tong D, Shao M, Wang S, Zhang Y, et al. Drivers of improved $\mathrm{PM}_{2.5}$ air quality in China from 2013 to 2017. Proc Natl Acad Sci. 2019;116(49):24463-9. https://doi.org/10.1073/pnas.1907956116.

4. Xue T, Zheng Y, Geng G, Xiao Q, Meng X, Wang M, et al. Estimating spatiotemporal variation in ambient ozone exposure during 2013-2017 
using a data-fusion model. Environ Sci Technol. 2020;54(23):14877-88. https://doi.org/10.1021/acs.est.0c03098.

5. Kuerban M, Waili Y, Fan F, Liu Y, Qin W, Dore AJ, et al. Spatio-temporal patterns of air pollution in China from 2015 to 2018 and implications for health risks. Environ Pollut. 2020;258:113659. https://doi.org/10.1016/j. envpol.2019.113659.

6. Wang F, Qiu X, Cao J, Peng L, Zhang N, Yan Y, et al. Policy-driven changes in the health risk of $\mathrm{PM}_{2.5}$ and $\mathrm{O}_{3}$ exposure in China during 2013-2018. Sci Total Environ. 2021;757:143775. https://doi.org/10.1016/j.scitotenv.2020.143 775.

7. Zhao H, Chen K, Liu Z, Zhang Y, Shao T, Zhang H. Coordinated control of $\mathrm{PM}_{2.5}$ and $\mathrm{O}_{3}$ is urgently needed in China after implementation of the "Air pollution prevention and control action plan". Chemosphere. 2021;270: 129441

8. Gu J, Shi Y, Zhu Y, Chen N, Wang H, Zhang Z, et al. Ambient air pollution and cause-specific risk of hospital admission in China: A nationwide timeseries study. Plos Med. 2020;17(e10031888).

9. Lim CC, Hayes RB, Ahn J, Shao Y, Silverman DT, Jones RR, et al. Long-Term Exposure to Ozone and Cause-Specific Mortality Risk in the United States. Am J Resp Crit Care. 2019;200(8):1022-31.

10. Vicedo-Cabrera AM, Sera F, Liu C, Armstrong B, Milojevic A, Guo Y, et al. Short term association between ozone and mortality: global two stage time series study in 406 locations in 20 countries. BMJ. 2020:m108.

11. Turner MC, Jerrett M, Pope CA, Krewski D, Gapstur SM, Diver WR, et al. Long-Term Ozone Exposure and Mortality in a Large Prospective Study. Am J Resp Crit Care. 2016;193(10):1134-42.

12. Di Q, Dai L, Wang Y, Zanobetti A, Choirat C, Schwartz JD, et al. Association of Short-term Exposure to Air Pollution With Mortality in Older Adults. JAMA. 2017;318(24):2446

13. Tao Y, Huang W, Huang X, Zhong L, Lu SE, Li Y, et al. Estimated acute effects of ambient ozone and nitrogen dioxide on mortality in the Pearl River Delta of southern China. Environ Health Perspect. 2012;120(3):393-8.

14. Raza A, Bellander T, Bero-Bedada G, Dahlquist M, Hollenberg J, Jonsson M, et al. Short-term effects of air pollution on out-of-hospital cardiac arrest in Stockholm. Eur Heart J. 2014;35(13):861-8.

15. Brook RD, Cakmak S, Turner MC, Brook JR, Crouse DL, Peters PA, et al. LongTerm Fine Particulate Matter Exposure and Mortality From Diabetes in Canada. Diabetes Care. 2013;36(10):3313-20.

16. Tonne C, Wilkinson P. Long-term exposure to air pollution is associated with survival following acute coronary syndrome. Eur Heart J. 2013;34(17):130611.

17. Pan W, Wu C, Chen M, Huang Y, Chen C, Su H, et al. Fine Particle Pollution, Alanine Transaminase, and Liver Cancer: A Taiwanese Prospective Cohort Study (REVEAL-HBV). JNCl. 2016;108(3).

18. Gao H, Shi J, Cheng H, Zhang Y, Zhang Y. The impact of long- and short-term exposure to different ambient air pollutants on cognitive function in China. Environ Int. 2021;151:106416. https:/doi.org/10.1016/j.envint.2021.106416.

19. Guo Y, Li S, Tian Z, Pan X, Zhang J, Williams G. The burden of air pollution on years of life lost in Beijing, China, 2004-08: retrospective regression analysis of daily deaths. BMJ. 2013;347(dec09 7):f7139.

20. Feng Z, De Marco A, Anav A, Gualtieri M, Sicard P, Tian H, et al. Economic losses due to ozone impacts on human health, forest productivity and crop yield across China. Environ Int. 2019;131:104966. https://doi.org/10.1016/j. envint.2019.104966.

21. Maji KJ, Namdeo A. Continuous increases of surface ozone and associated premature mortality growth in China during 2015-2019. Environ Pollut. 2021;269:116183. https://doi.org/10.1016/j.envpol.2020.116183.

22. Al-Kindi SG, Brook RD, Biswal S, Rajagopalan S. Environmental determinants of cardiovascular disease: lessons learned from air pollution. Nat Rev Cardiol. 2020;17(10):656-72.

23. Zhou W, Chen C, Lei L, Fu P, Sun Y. Temporal variations and spatial distributions of gaseous and particulate air pollutants and their health risks during 2015-2019 in China. Environ Pollut. 2021;272:116031. https://doi. org/10.1016/j.envpol.2020.116031.

24. Sandstrom T, Frew AJ, Svartengren M, Viegi G. The need for a focus on air pollution research in the elderly. Eur Respir J. 2003;21(Supplement 40):92S95S.

25. Cover $\mathrm{H}$, Irwin M. Immunity and depression: insomnia, retardation, and reduction of natural killer cell activity. J Behav Med. 1994;17(2):217-23.

26. Qiu H, Yu H, Wang $L$, Zhu X, Chen $M$, Zhou $L$, et al. The burden of overall and cause-specific respiratory morbidity due to ambient air pollution in
Sichuan Basin, China: a multi-city time-series analysis. Environ Res. 2018;167: 428-36. https://doi.org/10.1016/.jenvres.2018.08.011.

27. Zeng $Q$, Wu Z, Jiang G, Wu X, Li P, Ni Y, et al. The association between ambient inhalable particulate matter and the disease burden of respiratory disease: an ecological study based on ten-year time series data in Tianjin. China Environ Res. 2017;157:71-7. https://doi.org/10.1016/j.envres.2017.05. 004.

28. Xing Q, Sun Z, Tao Y, Zhang X, Miao S, Zheng C, et al. Impacts of urbanization on the temperature-cardiovascular mortality relationship in Beijing. China. Environ Res. 2020;191:110234. https://doi.org/10.1016/j. envres.2020.110234.

29. Zhou H, Geng H, Dong C, Bai T. The short-term harvesting effects of ambient particulate matter on mortality in Taiyuan elderly residents: a timeseries analysis with a generalized additive distributed lag model. Ecotox Environ Safe. 2021;207:111235. https://doi.org/10.1016/j.ecoenv.2020.111235.

30. Hu W, Chen Y, Chen J. Short-term effect of fine particular matter on daily hospitalizations for ischemic stroke: a time-series study in Yancheng. China Ecotox Environ Safe. 2021;208:111518. https://doi.org/10.1016/j.ecoenv.202 0.111518 .

31. Li M, Dong H, Wang B, Zhao W, Zare Sakhvidi MJ, Li L, et al. Association between ambient ozone pollution and mortality from a spectrum of causes in Guangzhou. China Sci Total Environ. 2021;754:142110. https://doi.org/10.1 016/.scitotenv.2020.142110.

32. Akaike H. Factor analysis and AIC. Psychometrika. 1987;3(52):317-33. https:// doi.org/10.1007/BF02294359

33. Bell ML, Zanobetti A, Dominici F. Evidence on vulnerability and susceptibility to health risks associated with short-term exposure to particulate matter: a systematic review and Meta-analysis. Am J Epidemiol. 2013;178(6):865-76. https://doi.org/10.1093/aje/kwt090.

34. Wang W, Parrish DD, Li X, Shao M, Liu Y, Mo Z, et al. Exploring the drivers of the increased ozone production in Beijing in summertime during 20052016. Atmos Chem Phys. 2020;20(24):15617-33. https://doi.org/10.5194/a cp-20-15617-2020.

35. Xu G, Ren X, Xiong K, Li L, Bi X, Wu Q. Analysis of the driving factors of $\mathrm{PM}_{2.5}$ concentration in the air: A case study of the Yangtze River Delta, China. Ecol Indic. 2020:110:105889.

36. Tang G, Zhu X, Xin J, Hu B, Song T, Sun Y, et al. Modelling study of boundary-layer ozone over northern China - part I: ozone budget in summer. Atmos Res. 2017;187:128-37. https://doi.org/10.1016/j.atmosres.201 6.10 .017 .

37. Wallington TJ, Sulbaek Andersen MP, Nielsen OJ. Atmospheric chemistry of short-chain haloolefins: photochemical ozone creation potentials (POCPS), global warming potentials (GWPs), and ozone depletion potentials (ODPs). Chemosphere. 2015;129:135-41. https://doi.org/10.1016/j.chemosphere.2014. 06.092.

38. Lei R, Zhu F, Cheng H, Liu J, Shen C, Zhang C, et al. Short-term effect of $\mathrm{PM}_{2.5} / \mathrm{O}_{3}$ on non-accidental and respiratory deaths in highly polluted area of China. Atmos Pollut Res. 2019;10(5):1412-9. https://doi.org/10.1016/j.apr.2 019.03.013.

39. LIN Zai-sheng LSWK. Time-series study on effects of low-concentration $\mathrm{PM}_{2.5}$ on mortality in elderly people in Fuzhou from 2015 to 2018. Environ Occup Med. 2020;2(37):157-161.

40. Dai L, Zanobetti A, Koutrakis P, Schwartz JD. Associations of fine particulate matter species with mortality in the United States: a multicity time-series analysis. Environ Health Persp. 2014;122(8):837-42. https://doi.org/10.1289/ ehp.1307568.

41. Liu C, Chen R, Sera F, Vicedo-Cabrera AM, Guo Y, Tong S, et al. Ambient particulate air pollution and daily mortality in 652 cities. N Engl I Med. 2019; 381(8):705-15. https://doi.org/10.1056/NEJMoa1817364.

42. Song W, Liu Y, Liu J, Tao N, Li Y, Liu Y, et al. The burden of air pollution and weather condition on daily respiratory deaths among older adults in China, Jinan from 2011 to 2017. Medicine. 2019;98(10):e14694. https://doi.org/10.1 097/MD.0000000000014694.

43. Guo B, Chen F, Deng Y, Zhang H, Qiao X, Qiao Z, et al. Using rush hour and daytime exposure indicators to estimate the short-term mortality effects of air pollution: A case study in the Sichuan Basin, China. Environ Pollut. 2018; 242(Pt B):1291-8.

44. Medina-Ramón M, Zanobetti A, Schwartz J. The effect of ozone and PM10 on hospital admissions for pneumonia and chronic obstructive pulmonary disease: a National Multicity Study. Am J Epidemiol. 2006;163(6):579-88. https://doi.org/10.1093/aje/kwj078. 
45. Crouse DL, Peters PA, Hystad P, Brook JR, van Donkelaar A, Martin RV, et al. Ambient $\mathrm{PM}_{2.5} \mathrm{O}_{3}$, and $\mathrm{NO}_{2}$ exposures and associations with mortality over 16 years of follow-up in the Canadian census health and environment cohort (CanCHEC). Environ Health Persp. 2015;123(11):1180-6. https://doi. org/10.1289/ehp.1409276.

46. Raza A, Dahlquist M, Lind T, Ljungman P. Susceptibility to short-term ozone exposure and cardiovascular and respiratory mortality by previous hospitalizations. Environ Health. 2018;17(1):37. https//doi.org/10.1186/s12940-018-0384-z.

47. Li K, Jacob DJ, Liao H, Zhu J, Shah V, Shen L, et al. A two-pollutant strategy for improving ozone and particulate air quality in China. Nat Geosci. 2019; 12(11):906-10. https://doi.org/10.1038/s41561-019-0464-x.

48. Costa AF, Hoek G, Brunekreef B. Ponce De Leon ACM. Air pollution and deaths among elderly residents of Sao Paulo, Brazil: an analysis of mortality displacement. Environ Health Persp. 2017;125(3):349-54. https://doi.org/1 0.1289/EHP98.

49. Shin HH, Gogna P, Maquiling A, Parajuli RP, Haque L, Burr B. Comparison of hospitalization and mortality associated with short-term exposure to ambient ozone and $\mathrm{PM}_{2.5}$ in Canada. Chemosphere. 2021;265:128683.

50. Hu K, Guo Y, Hu D, Du R, Yang X, Zhong J, et al. Mortality burden attributable to PM1 in Zhejiang province. China Environ Int. 2018;121(Pt 1): 515-22. https://doi.org/10.1016/j.envint.2018.09.033.

51. Clougherty JE. A growing role for gender analysis in air pollution epidemiology. Environ Health Perspect. 2010;1 18(2):167-176. https://doi. org/10.1289/ehp.0900994.

52. Prisby RD, Muller-Delp J, Delp MD, Nurkiewicz TR. Age, gender, and hormonal status modulate the vascular toxicity of the diesel exhaust extract Phenanthraquinone. J Toxic Environ Health A. 2008;71(7):464-70. https://doi. org/10.1080/15287390701839349.

53. Christidis T, Erickson AC, Pappin AJ, Crouse DL, Pinault LL, Weichenthal SA, et al. Low concentrations of fine particle air pollution and mortality in the Canadian Community Health Survey cohort. Environ Health-Glob. 2019;18(1).

54. Zhang F, Liu X, Zhou L, Yu Y, Wang L, Lu J, et al. Spatiotemporal patterns of particulate matter (PM) and associations between PM and mortality in Shenzhen, China. Bmc Public Health. 2016;16(1).

55. Wang L, Bai Y, Zhang F, Wang W, Liu X, Krafft T. Spatiotemporal patterns of ozone and cardiovascular and respiratory disease mortalities due to ozone in Shenzhen. Sustainability-Basel. 2017;9(4):559. https://doi.org/10.3390/su9040559,

56. Leyva Rodriguez L, Morera Alvarez O, Madruga Jimenez D, Cordero Cabrera HC, Pino Blanco RJ. In-hospital mortality due to respiratory diseases in the provincial Hospital of Cienfuegos. 2010-2014. Medisur-Revista De Ciencias Medicas De Cienfuegos. 2016;14(4):410-20.

57. Zanobetti A, Schwartz J. Is there adaptation in the ozone mortality relationship: a multi-city case-crossover analysis. Environ Health-Glob. 2008; 7(1):22. https://doi.org/10.1186/1476-069X-7-22.

58. Porter WC, Heald CL. The mechanisms and meteorological drivers of the summertime ozone-temperature relationship. Atmos Chem Phys. 2019; 19(21):13367-81. https://doi.org/10.5194/acp-19-13367-2019.

59. Huang Y, Yang Z, Gao Z. Contributions of Indoor and Outdoor Sources to Ozone in Residential Buildings in Nanjing. Int j env res pub he. 2019;16(258714).

60. Chen R, Cai J, Meng X, Kim H, Honda Y, Guo YL, et al. Ozone and daily mortality rate in 21 cities of East Asia: how does season modify the association? Am J Epidemiol. 2014;180(7):729-36. https://doi.org/10.1093/aje/kwu183.

61. Levy Jl, Chemerynski SM, Sarnat JA. Ozone exposure and mortality-an empiric Bayes Metaregression analysis. Epidemiology. 2005;16(4):458-68. https://doi.org/10.1097/01.ede.0000165820.08301.b3.

62. Sui X, Zhang J, Zhang Q, Sun S, Lei R, Zhang C, et al. The short-term effect of $\mathrm{PM}_{2.5} / \mathrm{O}_{3}$ on daily mortality from 2013 to 2018 in Hefei, China. Environ Geochem Hlth. 2020;43(1):153-69. https://doi.org/10.1007/s10653-02000689-x.

\section{Publisher's Note}

Springer Nature remains neutral with regard to jurisdictional claims in published maps and institutional affiliations.

Ready to submit your research? Choose BMC and benefit from:

- fast, convenient online submission

- thorough peer review by experienced researchers in your field

- rapid publication on acceptance

- support for research data, including large and complex data types

- gold Open Access which fosters wider collaboration and increased citations

- maximum visibility for your research: over $100 \mathrm{M}$ website views per year

At BMC, research is always in progress.

Learn more biomedcentral.com/submissions 